\title{
LUT
}

University

\section{The Antecedents of Individual Innovative Behaviour in Temporary Group Innovation}

\author{
Nisula Anna-Maija, Kianto Aino
}

This is a Final draft

version of a publication

published by Wiley

in Creativity and Innovation Management

DOI: $10.1111 /$ caim.12163

Copyright of the original publication: (C) John Wiley \& Sons

Please cite the publication as follows:

Nisula, A.-M., Kianto, A. (2016). The Antecedents of Individual Innovative Behaviour in Temporary Group Innovation. Creativity and Innovation Management, vol. 25, issue 4. pp. 431-444. DOI: 10.1111/caim.12163

This is a parallel published version of an original publication. This version can differ from the original published article. 


\title{
The Antecedents of Individual Innovative Behaviour in Temporary Group Innovation
}

\author{
Anna-Maija Nisula *) \\ anna-maija.nisula@lut.fi \\ Aino Kianto \\ aino.kianto@lut.fi \\ Lappeenranta University of Technology \\ School of Business and Management \\ Skinnarilankatu 34, 53850 Lappeenranta \\ Finland \\ *) corresponding author
}

Nisula, A. M., \& Kianto, A. (2016). The antecedents of individual innovative behaviour in temporary group innovation. Creativity and Innovation Management, 25(4), 431-444.

\begin{abstract}
This study examines the antecedents of individual innovative behavior in short-term innovation camp conditions. Innovation is increasingly a joint activity conducted in various kinds of temporary settings that collect widely diverse people together for a brief time to work for a particular problem. As innovativeness of interplaying individuals is key for the success of collaborative innovation, it is important to study what factors enhance individual innovative behavior in temporary settings. Data from 103 innovation camp participants were the basis of PLS-SEM analysis. Results show that individual creative self-efficacy, perceived task orientation, and experimentation have significant effects on individual innovative behavior. In contrast, participative safety, support for innovation, and vision are not associated with individual innovativeness. These findings suggest that the antecedents of individual innovativeness in temporary settings differ from those identified in conventional groups, pointing to a new field for future research.
\end{abstract}

Keywords: innovative behavior, temporary group, self-efficacy, group climate, PLS

\section{Introduction}

In the modern knowledge economy, innovation depends significantly on the ability to swiftly integrate different but interrelated kinds of knowledge to address complex open-ended problems (Grant, 1996; Lindkvist, 2005). Among the mechanisms for boosting innovation are so-called innovation camps, which are methods of organizing for creative development to prompt social innovations (Dawson \& Daniel, 2010), technology, design, and product development (Fuellerton et al., 1999). These events bring 
together people with divergent knowledge and heterogeneous backgrounds to solve complex problems through intensive and informal interaction in a very short timeframe.

The actualization of creativity and innovativeness among diverse participants in these temporary settings remain an open question. Collaborative innovation in short-term settings is produced via interlinked innovative behaviors by individuals. It can only occur when participants make contributions, express their ideas, support and build upon the ideas of others, make rapid experiments and playful realization of ideas, thereby further developing the joint creation. While the literature on innovation management includes substantial knowledge of the factors that generally influence individual innovativeness, a closer look at the empirical studies reveals that they have almost invariably been conducted in conditions of relatively long-standing, formal, and established organizational relationships and labor relations. However, temporary groups and other temporary forms differ from those of a long-standing in many respects (Hamish \& Wald, 2013; Saunders \& Ahuja, 2006; Bakker, 2010; Mayerson, Weick \& Kramer, 1996), and the antecedents of individual innovativeness in short-term creative collaborations remain an unexplored issue.

Innovation camps are set apart from everyday organizational life by two key features: their short time span (temporariness) and informality. Innovation camps are typically informal in the sense that they are set outside of a formal organizational framework; very often, their more or less overtly stated purpose is to create informal conditions where power relationships based on stable organizational structures, hierarchies, and status are played down and routine work patterns are minimized. Hence, an innovation camp aims to boost creativity and innovation by connecting and bringing together individuals in a liberated and playful environment where they are encouraged to actively and equally contribute and co-create joint solutions. In relation to these unique contexts, we argue that innovation camps serve as an ideal locus to examine the antecedents of individual innovative behaviors in dynamic conditions grounded by temporariness and informality.

The study address the question of what factors support innovative behavior in shortterm collaborative innovation settings by positing a model comprising both personal and contextual factors expected to influence individual innovative behavior in short-term creative collaboration and by empirically testing the model utilizing PLS-SEM with a survey data collected from 103 participants of two innovation camp events. The study contributes to the discussions of temporary collaborative innovation and temporary organization by obtaining knowledge about the antecedents of individual innovative behaviors within highly unique group settings. From the managerial perspective, the study provides knowledge for organizers of innovation events about the ways to foster individual innovativeness in temporary conditions.

\section{Innovation Camps as a Mechanism for Accelerating Collaborative Innovation}

Innovation camps are a popular method of organizing collaborative innovation by bringing together heterogeneous people to solve complex open-ended problems. Innovation camps can be internal (company driven), such as the IBM Corporate Service Corps and Smarter Cities Challenge and Siemens' Innovation Think Tank. In contrast, 
external camps are conducted outside an organization, often as joint activity with multiple stakeholders. These include e.g. the Social Innovation Camp (SICamp), a UK-based event replicated in several locations around the world since 2008, and the STEM Innovation Camp, which was conducted in 14 countries around the world in 2013.

External innovation camps can be seen as temporary organizations; likewise, the groups within these camps can be seen as temporary groups. In what follows, we discuss temporariness in terms of time, context, team/people, and task (Bakker, 2010). Time is the key determinant of temporariness (Bakker, 2010; Lanzara, 1983). Like temporary organizations, innovation camps occur for a short period of time, for example, to accomplish a particular task (Bakker, 2010; Hamis \& Wald, 2013). External innovation camps provide a context for group work and differ significantly from a formal organizational framework. They lack the characteristics of formal organizations, such as stable structures, processes and practices, pre-determined and stable roles (Bechky, 2006), organizational background, and memory (Mayerson et al., 1996). Thus, groups in an innovation camp context are informal by nature, and they have to rely more on selforganizing and informal coordination (Bechky, 2006; Prins, 2006) than on stable organizational mechanisms. In temporary organizational forms, the team can be understood as a collective of individuals (Saunders \& Ahuja, 2006) with particular skills, resources, and levels of interdependence (Lundin \& Söderholm, 1995). Innovation camps aim to build an informal context to connect diverse volunteers to work for a short time to boost innovation. In such camps, the participants are not members of the same organization; they do not necessarily have pre-existing relationships; and they do not share an organizational background. This diversity of perspectives and voices allows the possibility of innovative problem-solving, but it also poses challenges to collaboration and individual innovativeness in temporary settings. Innovation, then, depends significantly on the integration of participants' differing but interrelated knowledge bases.

The tasks of innovation camps varies and can range from generating ideas and solutions for innovation and development to producing economic value for a particular firm by developing its product and processes. The task (problem) definitions are typically unique, complex, and open-ended, requiring the integration of the ideas, insights, and perspectives of diverse actors to achieve novel solutions. This also refers to temporary organizations that exist to accomplish particular tasks (Lundin \& Söderholm, 1995), which, by their nature, are often more unique than routine. Hence, the intertwined influence of temporariness and informality is characteristic of innovation camps.

\section{Individual Innovative Behavior in Temporary Collaborative Settings}

Individual innovative behavior is an essential factor in the performance and competitiveness of work groups, organizations, and societies (Oldham \& Cummings, 1996). The foundation of all innovation are novel initiations and ideas, and it is individuals, or groups of them, who initiate, promote, modify, and ultimately realize those ideas (Scott \& Bruce, 1994). Individual innovative behavior consists of the generation of ideas, and activities to promote and actualize those ideas (Janssen, 2000; De Jong \& Den Hartog, 2010; Yuan \& Woodman, 2010) i.e. combining exploration with exploitation and creation with implementation. In practice, these behaviors work in complex confounded interaction with one another (cf. de Jong \& Den Hartog, 2010). As Scott and Bruce (1994, 582) put it, "individuals can be expected to be involved in any combination of these behaviors at any one time." Moreover, the complex mix of individual behaviors and 
contributions build the interdependence and social dynamics that enable the integration and synthesis of distributed knowledge, expertise, and efforts of diverse actors for particular tasks or goals. Thus, individual innovative behavior is crucial for temporary collaborative settings that are based on the contributions and joint creation of interplaying individuals.

Previous research has identified several antecedents of individual innovativeness relating to attributes of an individual and characteristics of the work context. Creativity (Amabile, 1988; Oldham \& Cummings 1996), problem-solving style (Scott \& Bruce, 1994), creativity skills (Fisher \& Amabile, 2009) and creative self-efficacy (Bandura, 1997; Tierney \& Farmer, 2002; Axtell et al., 2006) are such individual attributes. Individual innovativeness is likely to occur in a work context characterized, for instance, by cultural encouragement for efforts to introduce novel and creative outcomes (West \& Richter, 2009), practical support for innovation activities (Yuan \& Woodman, 2010), supportive leadership (De Jong \& Den Hartog, 2010; Scott \& Bruce, 1994), team climate (Axtell et al., 2006; Pirola-Merlo \& Mann, 2004; West 1990), and fluent interaction within the work group (Scott \& Bruce, 1994; Anderson \& West 1998).

However, temporary innovation settings represent an original and collaborative context which challenge individual innovativeness. While existing studies on individual innovative behavior have examined such contexts as research institute (De Jong \& Den Hartog, 2010), industrial and manufacturing companies (Janssen, 2000), a knowledgeintensive service firm (De Jong \& Den Hartog, 2010), shop floor employees in manufacturing industry (Axtell et al., 2000; Axtell et al., 2006), and in R\&D technology companies (Scott \& Bruce, 1994), they have retained the stable organizational setting as a tacit reference point, and focused on groups consisting of relatively similar members in terms of field of expertise, nature of tasks, and institutional commitments, set within particular boundary conditions. It seems that the question of individual innovativeness in the conditions of collaborative innovation with a limited time span (temporary) and informality has not been explicitly addressed so far in the literature. This is a crucial gap in existing knowledge, as work is increasingly conducted in various kinds of short-term, fluid, and dynamic social and institutional settings (Lindkvist, 2005; Mayerson, et al., 1996; Goodman \& Goodman, 1976; Bakker, 2010; Eksted et al. 1999; Bakker, 2010; Kellogg, et. al., 2006).

As it is not yet clear what factors enhance individual innovativeness in temporary and informal innovation settings, the study at hand takes as a reference point the current knowledge of stable organizational settings. The study adopts an interactionist perspective (Ross \& Nisbett 1991) to study the simultaneous effects of both personal attributes and situational constraints (Scott \& Bruce, 1994; Janssen, 2000; Fisher \& Amabile, 2009) on individual innovative behaviors. This perspective argues that individual behavior is based both on individual characteristics and situational factors. Concerning individual attributes, the very short period of time might pose pressure for individual innovativeness while informality might enable the freedom to express ideas and experience and thereby release individual innovativeness. Moreover, situational factors are contingent on an individual's subjective interpretation of the situation. Situations are rooted in one's social environment, in the group context where one finds 
oneself. As this perspective addresses individual interpretations of the social situation as a key contextual variable, it is well suited for addressing grounds of behavior in temporary settings where objective structures, clear norms, and shared routines might be absent but where each participant feels and interprets the situation in the innovation camp group. Thus, in our examination of innovativeness, we address both individual and situational (group) types of antecedents and discuss them in greater detail in what follows.

\section{Individual creative self-efficacy}

Individual creativity i.e. an individual's ability to produce novel ideas and initiatives (Amabile 1983; 1988) is key individual level antecedent of individual innovativeness. According to the self-efficacy theory of Bandura (1997) an individual's self-assessed creativity can be viewed as confidence in one's own abilities in the context of a given activity, such as creative thinking, seeing possibilities, generating new ideas and solutions. A higher belief in one's own creativity is more likely to lead to novel undertakings and performance, while a lower level of such belief may lead to behavior within the rules. Tierney and Farmer (2002) demonstrated this effect in the context of creativity, showing that creativity related self-efficacy predicts creative performance.

Furthermore, based on role identity theory, Farmer et al., (2003) have argued that identifying oneself as a creative person will lead to creative behaviors.

Thus, individual self-efficacy can be seen as a fundamental predictor of individual innovative behavior-fostering idea generation, finding effective means of social interaction and argument to attract supporters (the idea promotion dimension), and finding ways to build prototypes and rapidly test ideas (the idea realization dimension). An individual creativity belief may be an especially important antecedent of innovativeness in the context of temporary and informal group settings, where there are no stable and routinized interaction patterns or structures to lean upon, and where the viable ways of action have to be invented on the fly. On the basis, the following hypothesis is proposed:

H1: Individual creative self-efficacy is positively related with individual innovative behavior exhibited in temporary group settings.

\section{Perceived contextual factors}

In addition to individual attributes, it is suggested that individual innovative behaviour may be impacted by contextual factors. Short-lived innovation camps lack most of the contextual factors that are found to impact individual innovativeness in stable organizational settings, such as stable work group relations (Scott \& Bruce, 1994), organizational support for innovation and job requirements (Yuan \& Woodman, 2010), leadership (de Jong \& Den Hartog, 2010; Scott \& Bruce, 1994) and external work contacts (De Jong \& Den Hartog, 2010).

It is argued that the construct of climate is an especially suitable perspective from which to understand the antecedents of individual innovative behaviour in the context of short-term groups. This refers to the "psychological climate" of an individual, as 
constructed by their cognitive interpretation of a situation, and represents the signals received by the individual in relation to expectations for behavior and potential outcomes. Proponents of psychological climate theory posit that individuals respond to their cognitive representations and interpretations of situations, "rather than to the environments per se," and that climate is a key determinant of individual behavior (Scott \& Bruce, 1994). Climate is constructed according to team member perceptions of the group during collaborative situations as they unfold, and it does not necessitate a longstanding shared history or stable organizational structure for support. Climate is therefore likely to be an especially important contributor to individual behavior in the context of temporary and informal collaborations where the constraints of more stable and routinized activities are absent.

The best-known model of how group-level contextual issues foster innovative behavior is West's (1990) theory of team climate for innovation, which identifies four antecedents of innovativeness: participative safety, support for innovation, vision, and task orientation. As there are no previous studies examining the effects of team climate factors on individual innovative behavior in very short-term temporary group innovation, we posit a positive hypothesis for all relationships in the research model, which assumes that when a group member supports an individual in ways that foster the emergence of innovation, the individual is more likely to see the group as a whole as being supportive of innovation. Therefore, it may be expected that the degree to which camp participants perceive the group climate as supportive of innovation will affect their innovativeness. Figure 1 presents the theoretical model.

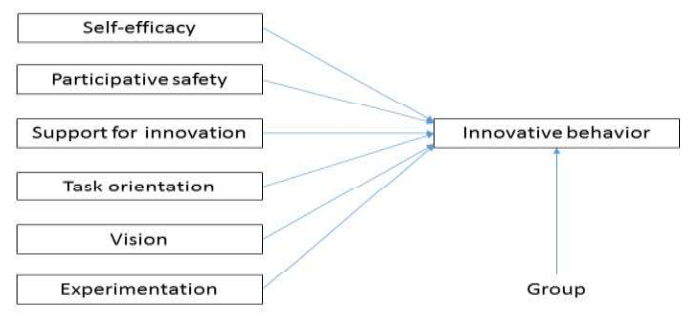

Figure 1: Variables and causal relations (hypothesized paths) between the variables.

\section{Participative safety}

Participative safety is seen as an important facilitator of both team innovation (West, 1990) and individual innovation (Pirola-Merlo \& Mann, 2004), involving frequent dialogical interaction and widespread participation in the group, conducted in a positive, supportive, and interpersonally safe environment (West 1990). The more people can 
participate in decision-making through interaction and information sharing, the more likely they commit to the outcomes of decisions and offer new ideas about possible improvements.

It is proposed here that participative safety, which has been shown to be an important antecedent of innovation in formal work group settings, is an important facilitator of innovativeness in innovation camp settings. The members of temporary innovation groups do not share a mutual history or knowledge of one another's skills and personalities. This lack of familiarity might potentially make it more threatening to suggest new ideas. It is proposed that while building an atmosphere of participative safety may prove challenging in temporary groups, it is especially important for supporting the innovativeness of their members. Our second hypothesis suggests that when an individual perceives the climate of the group to be safe and encouraging of participation, the individual is more likely to behave in an innovative manner:

H2: Perceived participative safety is positively related with individual innovative behavior in temporary group settings

\section{Support for innovation}

Support for innovation is identified as an antecedent of both team innovation (Anderson \& West, 1998) and individual innovation (Pirola-Merlo \& Mann, 2004; Yuan $\&$ Woodman, 2010). It concerns "the expectation, approval and practical support of attempts to introduce new and improved ways of doing things in the work environment" (West, 1990, 338). The expectation and approval of innovativeness lead individuals to understand that being innovative is a desirable image and that engaging in innovative behavior will increase their status (Yuan \& Woodman, 2010). While in conventional organizational settings this expectation, related compensation and support, may come from the supervisor or human resource management systems, in temporary groups these may not exist or be at least relatively less binding. However, also in such groups individuals might feel the pressure and be motivated to be innovative through tasks, identity goals and social support. The task of the group might require thinking and doing new things, thus creating an expectation of innovation. Individuals may also find the social image and identity of an innovative person desirable, and social recognition for innovativeness might spur them to be more innovative. Additionally, support and participation of the other group members is an important form of practical support for innovation. When individuals get help and support from others in developing and implementing their ideas, this enables them to be more innovative. This seems likely to be true in temporary and informal contexts as well as in more stable situations, giving rise to the next hypothesis:

H3: Perceived support for innovation in the group is positively related with individual innovative behavior in temporary group settings 


\section{Task orientation}

Task orientation denotes a general commitment to producing work to accomplishing a task with a high standard, creating a group environment in which practices are questioned in a constructive manner in order to identify possibilities for improvement, and where differing viewpoints are cherished rather than suppressed (West, 1990). Allowing and encouraging minority views and dissenting perspectives has been found useful for creativity and innovation (Tjosvold, 1992; De Drew \& West, 2001).

High performance and interesting aims in a group motivate and encourage individual members to put in their best effort also in temporary group settings. The positive sense of challenge created by high goals spurs internal motivation for creativity (Amabile, 1988). Encouragement to voice opinions and constructive questioning also make individual engagement in innovation more likely. Overall, perceived task orientation and engagement will encourage and motivate individuals to be more innovative and to persistently strive for excellent outcomes, and it is therefore hypothesized that task orientation directly affects innovativeness:

H4: Perceived task orientation is positively related with individual innovative behavior in temporary group settings

\section{Vision}

The element of vision is defined as an "idea of a valued outcome that represents a higher order goal and a motivating force at work" (West, 1990, 310). Work groups with clearly defined and valued objectives are likely to develop new goal-appropriate methods of working because they are motivated and their efforts have focus and direction. Shared vision is seen to affect individual innovative behavior. The literature suggests that clearly defined, shared, and valued objectives and visions promote innovativeness in individuals, teams, and organizations (Anderson \& West, 1998).

Shared vision is likely to be an important facilitator in short-term group settings. Having a shared goal to guide development work is likely to be especially influential in conditions of the short timeframe for producing innovative results. Clear and attainable goals for the group's work enable individuals to focus on the task at hand. By producing a positive sense of challenge in the work and enabling a focus on the work itself, shared vision increases internal task motivation, which in turn is a key promoter of individual creativity (Amabile, 1988). Shared vision may be especially important for integrating knowledge in groups where participants are highly dissimilar and come from different backgrounds, giving a direction to knowledge creation, stimulating the intellectual passion of individuals, and encouraging them to create knowledge (Nonaka \& Toyama, 2005). In knowledge-based endeavors such as innovation camps, then, it is posited that the shared vision of group goals could be especially important in supporting innovativeness:

H5: Shared vision is positively related with individual innovative behavior in temporary group settings 


\section{Experimentation}

Experimentation, i.e. climate of tolerance for mistakes, playfulness, freedom, and encouragement to experiment, was introduced by Vera and Crossan (2005) in the context of team improvisation. Short timeframes can stimulate improvisational or self-organized interaction, requiring tolerance of ambiguity, individual initiative-taking, experimentation, and ability to cope with serendipities and unplanned interactions (Kamoche, Cunha \& Cunha, 2002; Fisher \& Amabile, 2009), all of which expose the deficits in conventional forms of organizing (Kamoche et al., 2002). Experimentation (Eisenhardt \& Tabrizi, 1995; Vera \& Crossan, 2005) is characteristic of group improvisation, which is also found in temporary group settings. It may therefore be anticipated that experimentation feeds individual innovativeness in a temporary group innovation context:

H6: Experimentation is positively related to individual innovative behavior in temporary group settings

\section{Methodology}

\section{Data collection}

The data was collected from two international ACSI (Aalto Camp for Societal Innovation) camps in Finland in 2011 and 2012. In ACSI camps, participants with highly divergent cultural, ethnic, and professional backgrounds were brought together from around the world for an intensive one-week event with a view to solving societal problems posed by Finnish stakeholders.

The participants worked in groups, and each group worked on a single problem. The problems were broadly defined by the stakeholders, and each group had the possibility to modify and redefine their problem while developing a solution for it. The problems included: "creating new models for work-based learning," "enriching negotiation in search of common ground," and "finding novel ways to increase innovation practices in a city environment." The course for the one-week camp was as follows: during the first two days, the group got to familiarize itself both with each other as group members and the problem of the stakeholder. Over the following three days, the group worked to redefine and formulate the problem to be solved (goal) and to find and develop solutions for the problem by simultaneously redefining and crystallizing their goal further. During the last two days, the groups focused on implementing their solutions, including a presentation (implementation) of the solution in the final exhibition, which was open to a broader audience. The camp organizers put various support interventions and informative lectures in place to encourage all groups to proceed in a similar sequence throughout the camp's duration.

In total, seventeen groups from two ACSI camps were included in the study. The groups comprised ten to fourteen members, with one group having eighteen members. A web-based questionnaire was used to collect information from the participants after the camp. 


\section{Measurements}

All the constructs were measured by use of a seven-point Likert-type scale as follows: individual creative self-efficacy was measured by a three-item scale adopted from Tierney and Farmer (2002); experimentation was measured by a three-item scale (Vera \& Crossan, 2005); both task orientation and vision were measured using three-item scales from Kivimäki and Elovainio (1999) and Anderson and West (1998); and scales for participatory safety (five items) and support for innovation (four items) were adopted from Anderson and West (1998). The dependent variable, innovative work behavior, was measured by a six-item scale adopted from Janssen (2000). We used the group size to control for the potential impact of it on innovative work behavior, and the group number for studying whether there were any differences between the responses across groups.

\section{Descriptive statistics}

Of the respondents $(\mathrm{N}=103), 44.7 \%(\mathrm{~N}=46)$ were female and $55.3 \%(\mathrm{~N}=57)$ were male. In terms of educational attainment, the distribution of the respondents was as follows: 1.9\% $(\mathrm{N}=2)$ matriculation examination; $11.7(\mathrm{~N}=12)$ lower academic degree; 64.1\% $(\mathrm{N}=66)$ higher academic degree; and 22.3\% ( $=23)$ doctoral degree. The age distribution of the respondents was as follows: $23.1 \%(\mathrm{~N}=24)$ were under 30 years old; 47.4\% $(\mathrm{N}=49)$ were between 31 and 50 years; $23.0 \%(\mathrm{~N}=23)$ were between 51 and 60 years; and $6.5 \%(\mathrm{~N}=7)$ were over 60 years.

Regarding the common method bias in self-report measures, we consider that when the focus of the study is on individual behaviour and on the effect of perceived grouplevel factors on it, the self-report is the most relevant measurement method, because the individuals themselves are the best to evaluate the issues leading to their innovative behaviour (Shalley et al., 2009; Conway \& Lance, 2010). Additionally, the largest factor accounted for 39.1\% assessed with the Harman's one-factor test (Podsakoff et al., 2003), and the common method bias was not a concern.

\section{Analysis and Results}

\section{Data analysis}

The Partial Least Square (PLS) SEM analysis was used to assess the hypothesized causal relationships between the variables. PLS handles the kind of non-normally distributed data well and is the preferred method for analysis of small sample sizes and in exploratory studies (Hair, Ringle \& Sarstedt, 2011). One more advantage of the PSL is that the Fornell-Larcker criterion used in reflective models discloses collinearity problems in the inner model (Hair, et al., 2011).

\section{Measurement model}

Composite reliability values of the constructs varied between 0.83-0.95, all above the suggested value of 0.70 (Nunnally \& Bernstein, 1994; Hair et al., 2011), demonstrating high levels of internal consistency reliability (Table 1). 
Convergent validity of the constructs, based on the average variance extracted (AVE) value, showed high levels of validity. AVE values of the constructs varied between $0.62-$ 0.82 (Table 1).

Discriminant validity was assessed by use of the Fornell-Larcker (1981) criterion (Hair et al., 2011). More specifically, the square root of AVE (on the diagonal in Table 1) was compared with the correlations between latent constructs. All the comparative correlations were lower than the square root of the AVE, so establishing discriminant validity (Hair et al. 2011).

Table 1: Construct statistics and correlation matrix

\begin{tabular}{lccccccccc} 
Construct & CR & AVE & 1 & 2 & 3 & 4 & 5 & 6 & 7 \\
\hline 1.Experimentation & 0.87 & 0.69 & $\mathbf{0 . 8 3}$ & & & & & & \\
2.Self-efficacy & 0.83 & 0.62 & 0.52 & $\mathbf{0 . 7 8}$ & & & & & \\
3.Innovative behavior & 0.93 & 0.67 & 0.78 & 0.60 & $\mathbf{0 . 8 1}$ & & & & \\
4.Participative safety & 0.95 & 0.82 & 0.59 & 0.53 & 0.64 & $\mathbf{0 . 9 1}$ & & & \\
5.Support & 0.92 & 0.73 & 0.62 & 0.47 & 0.65 & 0.82 & $\mathbf{0 . 8 5}$ & & \\
6.Task orientation & 0.87 & 0.69 & 0.71 & 0.40 & 0.74 & 0.79 & 0.80 & $\mathbf{0 . 8 3}$ & \\
7.Vision & 0.86 & 0.68 & 0.52 & 0.59 & 0.56 & 0.76 & 0.79 & 0.67 & $\mathbf{0 . 8 2}$
\end{tabular}

\section{Model analysis}

Table 2 shows the results of the model analysis (structural model). The path between self-efficacy and individual innovative behavior was significant and positive $(\mathrm{t}=2.15)$, supporting hypothesis H1. The path between task orientation and innovative behavior was also significant $(\mathrm{t}=2.23)$, supporting hypothesis $\mathrm{H} 4$. The path between experimentation and individual innovative behavior was significant and positive $(\mathrm{t}=$ 2.99), supporting hypothesis H6. In contrast, non-significant effects were found for constructs of participatory safety $(\mathrm{t}=0.15)$, support for innovation $(\mathrm{t}=0.30)$ and vision $(\mathrm{t}=0.91)$, and so hypotheses H2, H3, and H5 were not supported. The effect of control variables, group size $(\mathrm{t}=1.21)$ and group number $(\mathrm{t}=0.67)$ were non-significant.

The coefficient of determination $\left(\mathrm{R}^{2}\right)$ represents the model's predictive accuracy. For the key construct (individual innovative behavior), the $\mathrm{R}^{2}$ value of 0.733 was substantial (Hair et al., 2011), and the model explained $73.3 \%$ of individual innovative behavior.

Table 2: Testing the model

\begin{tabular}{lccccc} 
Path & $\begin{array}{c}\text { Path } \\
\text { coefficient }\end{array}$ & $\begin{array}{c}\text { Standard } \\
\text { Deviation }\end{array}$ & $\begin{array}{c}\text { Standard } \\
\text { Error }\end{array}$ & $\begin{array}{c}\text { T } \\
\text { Statistics }\end{array}$ \\
\hline H1: Self-efficacy -> INNOBEH & 0.2818 & 0.1308 & 0.1308 & 2.15 & $* *$ \\
H2: Participatory safety -> INNOBEH & -0.0228 & 0.1481 & 0.1481 & 0.15 \\
H3: Support for innovation -> INNOBEH & 0.0377 & 0.1247 & 0.1247 & 0.30 & $*$ \\
H4: Task orientation -> INNOBEH & 0.4132 & 0.1853 & 0.1853 & 2.23 & $* *$ \\
H5: Vision -> INNOBEH & -0.0963 & 0.1057 & 0.1057 & 0.91 & \\
H6: Experimentation -> INNOBEH & 0.3877 & 0.1296 & 0.1296 & 2.99 & $* *$ \\
Group size -> INNOBEH & -0.0626 & 0.0517 & 0.0517 & 1.21 & 0.67
\end{tabular}




\section{Discussion}

Drawing from the current research conducted in conventional organizations, this study explored both individual-level the group-level factors influencing individual innovative behavior in temporary and informal group innovation settings.

The results show that individual self-efficacy and the perceived contextual factors of task orientation and experimentation supporting climate had an impact on individual innovative behavior. Conversely, participative safety, support for innovation and vision were found not to be related to individual innovative behavior. Thus antecedents of individual innovative behavior in temporary group innovation settings are different from those in conventional organizational settings.

Concerning the impact of individual attributes on innovativeness, the results of the study confirm the significance of individuals' creative self-efficacy on innovative behavior in temporary settings, and demonstrates that the confidence in one's creative abilities promotes innovativeness in short time frame activities, just like it does in more stable contexts (e.g., Amabile, 1983; 1988; Tierney et al., 1999; Bandura, 1997)

Of the perceived contextual factors, task orientation was found to be an antecedent of individual innovative behavior. Innovation camps, like temporary settings in general, exist to perform particular tasks. Thus, it is likely that the participants are motivated to be innovative and therefore place emphasis on accomplishing this task. This finding aligns with conceptual studies suggesting that task orientation is an especially important factor in temporary teams (Saunders \& Ahuja, 2006; Bakker, 2010). Additionally, previous studies indicate that people participate in various creative events to experience positive feelings of competence, autonomy, and task enjoyment (Dahl \& Moreau, 2007), which might also be the case for innovation camps. Thus, the tasks to be performed and the goals to be achieved are the drivers of individual innovativeness in short-term innovation camps.

Additionally, the findings indicate that an experimentation-friendly climate supports individual innovative behavior. It seems that this type of a climate is essential for achieving goals within time constraints and when participants are not familiar with one another and do not have the same practices, history, habits, or culture. Drawing upon work on team improvisation (Vera \& Crossan, 2005; Kamoche et al., 2002), this finding extends the existing understanding of the factors affecting individual innovative behavior in short-term innovation camps. Innovation camps, similar to team improvisation and self-organized group interactions, are characterized by playfulness, experimentation, riskand initiative-taking, and an ability to cope with serendipities and unplanned interactions (Kamoche et al., 2002), which seem to trigger individual innovative behaviors in this setting as group conditions are built upon interaction between the participating members.

Surprisingly, participative safety, support for innovation, and vision were found not to be related to individual innovative behavior in this study. In terms of the relevance of participative safety to individual innovative behavior, previous studies conducted in stable organizational settings show mixed results. Whereas the majority of studies show that participative safety is critical for individual innovativeness, Axtell et al. (2000) found 
participatory safety to be non-significant for both the suggestion and implementation of ideas regarding the innovativeness of shop-floor employees. One explanation for these results might be that the participants involved in the innovation camp were volunteers who were interested in a joint solution to the complex problem with which they were faced. Such an open-ended joint problem might stimulate participants who seek exploration, who are motivated, and who are able to work in conditions of uncertainty. In contrast, in stable organizational settings, expectations of risk or gain to one's image may impact individual innovative behaviour more (Yuan \& Woodman, 2010) than in a shortterm group innovation context where people are motivated, engaged, and are unlikely to meet again once the event has ended. Another explanation is that individuals participating in innovation camps are highly interested in the topic of the camp or joint creation in general, and the value of participation depends on their experiences in terms of knowledge and competence contributions (Dahl \& Moreau, 2007) and joint creation.

Another explanation for the surprising findings is that participative safety, support and vision may mediate the relationship between individual attributes and individual innovative behavior. It follows that future studies of antecedents of individual innovative behavior should include measures of the mediation and interaction effects of both individual attributes and the team climate.

\section{Conclusions}

The previous literature leaves two important questions unanswered. First, what kinds of factors impact individual innovativeness in temporary collaborative settings? Second, do the drivers of individual innovativeness in temporary informal collaborative settings match the antecedents found in more stable conditions? Some factors that have previously been found to impact innovative behavior in the workplace may not exert influence in the context of temporary informal innovation camps. For example, Yuan and Woodman (2010) found that employee engagement in innovative behavior at work was explained by the expected positive impact on employees' work performance and the expected risks and gains regarding their image. In the case of short-term cross-organizational collaboration in which future interactions between members are improbable, such effects are less likely.

The present study contributes to the understanding of individual innovative behavior in a range of contexts by demonstrating the kinds of factors affecting individual innovativeness in temporary collaborative settings - factors that have not been examined in previous studies (Saunders \& Ahuja, 2006; Bakker, 2010). More specifically, the study contributes to the literature on temporary and informal collaborative creation (innovation) with knowledge about the antecedents of individual innovative behaviors within highly unique innovation settings. This is important because collaborative innovation in such settings depends on the innovative behaviors of interacting individuals. The study also contributes to the discussion about the nature of temporary collaboration and suggests that it would better to see such collaboration in terms of individual people coming together to work interdependently together for a short period of time, rather than as internally homogenous groups (Saunders \& Ahuja, 2006; Lundin \& Söderholm, 1995). In a broader sense, the study contributes to the little-explored field of temporary 
organizations (Bryman et al., 1987; Saunders \& Ahuja, 2006; Bakker, 2010) by focusing on the behaviors of individuals within the context of temporary innovation camps.

At a practical level, the present findings invite a question: if we want to increase innovativeness in short-term endeavors, should we be using the same mechanisms that are used in formal organizational settings? Based on these results, it seems that the measures that have been proven to be effective in formal organizational settings do not have the same impact in short-term informal groups. This study provides information for practitioners aiming to increase innovativeness in temporary innovation settings. More specifically, the study informs organizers of temporary innovation events; that individual innovative behavior is the basis for collaborative innovation; that it stands for individual creative self-efficacy (confidence); and that it can be fostered by providing a climate for experimentation (space) and a direction for tasks (or problem-solving). Consequently, when defining a task or problem, the collection of individual people (group), their interactions, and the context for the group should be consciously built and facilitated in supporting the maintenance of high interest in a task.

The paper also adds to the discussion on the respective roles of individual and contextual factors in the construction of innovative behavior by demonstrating that both individual and group factors impact innovativeness in temporary and informal contexts. Finally, the findings of the study indicate that individual innovativeness is driven differently in temporary and informal collaborative contexts than in more stable and bounded organizational structures, thus supporting studies calling for further research on the informality and temporality of organizing.

While much of the research on innovation and creativity at work has been conducted in the context of NPD and other R\&D teams, it is argued that the findings of these studies should not be directly applied to very short-term collaborative settings such as innovation camps. This also implies that the notions of temporality and informality should be given greater attention in innovation research.

\section{Limitations}

The key limitation of the paper is that all observations were collected from the participants of one very specific type of innovation camp. The complex open-ended nature of the problems addressed, the divergence of participant backgrounds, and the selfdirected working principles employed in ACSI made the study a revelatory research context for examining individual innovative behavior under temporary conditions. However, the findings of this study should be validated in other kinds of temporary innovation settings in order to establish how the results may be affected by various boundary conditions arising from how camps or other temporary settings are organized.

Another interesting topic would be to address various solutions for organizing collaborative innovation, with varying degrees of temporariness and informality. An interesting further research question would be to look at different kinds of such arrangements, for instance, from longer to shorter terms and with varying degrees of informality. This would also enable a more in-depth disentanglement of the impacts of temporariness and informality to individual innovativeness. 
Worthy of discussion is also the use of self-reported data set (the data for all the variables were collected from a single source: the individual innovation camp participants). In this study the self-reported data is justified as we were interested in individual perceptions (Convey \& Lance, 2010). Additionally, the Harman test demonstrated that common method bias was not a problem in the dataset. In future studies data from several sources would be preferable; these studies might utilize external or peer assessments or objective criteria as indicators of individual innovative behavior. Additionally, group-level creativity and innovation performance might also be examined.

In general, the present results suggest that group climate characteristics that support innovativeness in short-term collaborative settings differ from those that are effective in more stable work contexts. It therefore seems that temporality should be addressed as a contingency factor in organizational research, at least with respect to innovation. To examine this issue further, additional empirical studies are needed on temporary teams and organizations of various kinds.

\section{REFERENCES}

Amabile T.M. (1983) The social psychology of creativity: A componential conceptualization. Journal of Personality and Social Psychology, 45, 357-376.

Amabile, T.M. (1988) A model of creativity and innovation in organizations. In Staw, B.M. and Cummings, L.L. (eds.), Research in organizational behavior 10, JAI, Greenwich, CT, pp. 123-167.

Anderson, N. and West, M.A. (1998) Measuring climate for work group innovation: Development and validation of the team climate inventory. Journal of Organizational Behaviour, 19, 235-258.

Axtell, C.M., Holman, D.J., Unsworth, K.L., Wall, T.D. and Waterson, P. E. (2000) Shopfloor innovation: facilitating the suggestion and implementation of ideas. Journal of Occupational and Organizational Psychology, 73, 265-285.

Axtell, C., Holman, D. and Wall, T. (2006) Promoting innovation: a change study. Journal of Occupational and Organizational Psychology, 79, 509-516.

Bakker, R.M. (2010) Taking stock of temporary organizational forms: A systematic review and research agenda. International Journal of Management Reviews, 12, 466-486.

Bandura, A. (1997) Self-efficacy: The Exercise of Control. W.H. Freeman and Company, New York, USA.

Barclay, D.W., Higgins, C.A. and Thompson, R. (1995) The partial least squares approach to causal modeling: personal computer adoption and use as illustration. Technology Studies, 2 (2), 285-309.

Bechky, B. A. (2006) Gaffers, gofers, and grips: Role-based coordination in temporary organizations. Organization Science, 17(1), 3-21.

Bryman, A., Bresnen, M., Beardsworth, A.D., Ford, J. and Keil, E.T. (1987) The concept of the temporary system: the case of the construction project. In Di Tomaso, N. and Bacharach, S.B. (eds.), Research in the Sociology of Organizations 5, JAI Press, Greenwich, CT, pp. 253-283.

Conway, J. M., \& Lance, C. E. (2010). What reviewers should expect from authors regarding common method bias in organizational research. Journal of Business and Psychology, 25(3), 325-334. 
Dahl, D.W. and Moreau, P.C. (2007) Thinking inside the box: why consumers enjoy constrained creative experience. Journal of Marketing Research, 2007, 357-369.

Dawson, P. and Daniel, L. (2010) Understanding social innovation: a provisional framework, International Journal of Technology Management, 51, 1, 9-21.

De Drew, C.K.W. and West, M. (2001) Minority dissent and team innovation: the importance of participation in decision making. Journal of Applied Psychology, 86 (6), 1191-1201. doi: http://psycnet.apa.org/?\&fa=main.doiLanding\&doi=10.1037/0021-9010.86.6.1191

De Jong, J.P.J. and Den Hartog, D.N. (2010) Measuring innovative work behavior. Creativity and Innovation Management, 19 (1), 23-36.

Eisenhardt, K.M. and Tabrizi, B.N. (1995) Accelerating adaptive processes: product innovation in the global computer industry. Administrative Science Quarterly, 40 (1), 84-110.

Eksted, E., Lundin, R.A., Söderholm, A. and Wirdenius, H. (1999) Peripety in an R\&D drama: capturing a turnaround in project dynamics. Organization Studies, 25, 1557-1578.

Farmer, S., Tierney, P. and Kung-McIntyre, K. (2003) Employee creativity in Taiwan: An application of role identity theory. Academy of Management Journal, 46 (5), 618-630.

Fisher, C.M. and Amabile, T. (2009) Creativity, improvisation and organizations. In Richards, T., Runco, M.A. and Monger, S. (eds), The Routledge Companion to Creativity, Routledge, Taylor and Francis, pp.224.

Fornell, C. and Larcker, F. (1981) Evaluating Structural Equation Models with Unobservable Variables and Measurement Error. Journal of Marketing Research, 18 (1), 39-50.

Fullerton, R., Linster, B.G., MCKee, M. and Slate, S. (1999) An experimental investigation of research tournaments. Economic Inquiry, 37, 624-636.

Goodman, R.A. and Goodman, L.P. (1976) Some management issues in temporary systems: a study of professional development and manpower-the theatre case. Administrative Science Quarterly, 21, 494501.

Grant, R. (1996) Toward a knowledge-based theory of the firm. Strategic Management Journal, 17, Special Issue: Knowledge and the Firm (Winter 1996), 109-122.

Hair, J.F., Ringle, C.M. and Sarstedt, M. (2011) PLS-SEM: indeed a silver bullet. Journal of Marketing Theory and Practice, 19 (2), 139-151.

Hamisch, B. and Wald, A. (2014) Effects of complexity on the success of temporary organizations: Relationship quality and transparency as substitutes for formal coordination mechanisms. Scandinavian Journal of Management, 30 (2), 197-213.

Janssen, O. (2000) Job demands, perceptions of effort-reward fairness and innovative work behaviour. Journal of Occupational and Organizational Psychology, 73, 287-302.

Kamoche, K.N., Cunha, M.P.E. and Cunha, J.V. (2002) Organizational Improvisation. Routledge, Taylor \& Francis Group, London.

Kivimäki, M. and Elovainio, M. (1999) A short version of the Team Climate Inventory: Development and psychometric properties. Journal of Occupational and Organizational Psychology, 72 (2), 241-246. 
Lindkvist, L. (2005) Knowledge communities and knowledge collectives: A Typology of Knowledge Work in Groups. Journal of Management Studies 4 (6), 1189-1210.

Mayerson, D., Weick, K.E. and Kramer, R.M. (1996) Swift trust and temporary groups. In Kramer, R.M. and Tyler, T. R. (eds.), Trust in Organizations: Frontiers of Theory and Research, Sage, Thousand Oaks, CA, pp. 166-195.

Nonaka, I. and Toyama, R. (2005) The theory of the knowledge-creating firm: subjectivity, objectivity and synthesis. Industrial and Corporate Change, 14 (3), 419-436.

Nunnally, J.C. and Bernstein, I. (1994) Psychometric Theory, 3rd edn. McGraw-Hill, New York.

Oldham, G.R. and Cummings, A. (1996) Employee creativity: Personal and contextual factors at work. Academy of Management Journal, 39, 607-634.

Pirola-Merlo, A. and Mann, L. (2004) The relationship between individual creativity and team creativity: aggregating across people and time. Journal of Organizational Behaviour, 25, 235-257.

Podsakoff, P.M., MacKenzie, S.B., Lee, J.Y. and Podsakoff, N.P. (2003) Common Method Biases in Behavioral Research: A Critical Review of the Literature and Recommended Remedies. Journal of Applied Psychology, 88, 879-903.

Prins, S. (2006) The psychodynamic perspective in organizational research: Making sense of the dynamics of direction setting in emergent collaborative process. The British Psychological Society, 79, 335-355.

Ross, L. and Nisbett, R. (1991) The person and the situation: Perspectives of social psychology, McGrawHill, New York.

Saunders, C.S. and Ahuja, M.K. (2006) Are all distributed teams the same? Differentiating between temporary and ongoing distributed teams. Small Group Research, 37, 662-700.

Scott, S. and Bruce, R. (1994) Determinants of innovative behavior: A path model of individual innovation in the workplace. Academy of Management Journal, 37, 580-607.

Shalley, G., Gilson, L., and Blum, T. (2009). Interactive effect of growth need strength, work context, and job complexity on self-reported creative performance. Academy of Management Journal, 52, 489-505.

Tierney, P. and Farmer, S. (2002) Creative self-efficacy: Its potential antecedents and relationship to creative performance. Academy of Management Journal, 45 (6), 1137-1148.

Tierney, P., Farmer, S.M. and Graen, G.B. (1999) An examination of leadership and employee creativity: The relevance of traits and relationships. Personnel Psychology, 52, 591-620.

Tjosvold, D. (1998) Cooperative and competitive goal approach to conflict: accomplishments and challenges. Applied Psychology, 47 (3), 285-313.

Vera, D. and Crossan, M. (2005) Improvisation and innovative performance in teams. Organization Science, 3, 203-224.

West, M.A. (1990) The social psychology of innovation in groups. In West, M.A. and Farr, J.L. (eds.), Innovation and Creativity at Work: Psychological and Organizational Strategies, Wiley, Chichester.

West, M.A. (2002) Sparkling fountains or stagnant ponds: An integrative model of creativity and innovation implementation in work groups. Applied Psychology: An International Review, 51, 355-387. 
West, M.A. and Richter, A.W. (2009) Climates and cultures for Innovation and creativity at Work. In:

Zhou, J. \& Shalley, C. E. (eds.), Handbook of Organizational Creativity, Psychology Press, Taylor \& Francis Group, New York, pp. 211-236.

Yuan, F. and Woodman, R.W. (2010) Innovative behaviour in the workplace: the role of performance and image outcome expectations. Academy of Management Journal, 53 (2), 323-342.

APPENDIX I

Item descriptives table

\begin{tabular}{|c|c|c|c|c|c|}
\hline Construct & Loading & Mean & SD & $\begin{array}{l}\text { Composite } \\
\text { reliability }\end{array}$ & AVE \\
\hline Experimentation (Vera and Crossan, 2005) & & 5.45 & 1.321 & 0.87 & 0.69 \\
\hline In our group, errors were considered as a source of learning & 0.75 & & & & \\
\hline In our group, there was freedom to experiment & 0.88 & & & & \\
\hline $\begin{array}{l}\text { In our group, we were encouraged to take risks when } \\
\text { developing new ideas }\end{array}$ & 0.86 & & & & \\
\hline Self-efficacy (Tierney \& Farmer, 2002) & & 5.50 & 1.052 & 0.83 & 0.62 \\
\hline I generate a lot of creative ideas & 0.92 & & & & \\
\hline I can think creatively & 0.69 & & & & \\
\hline I do things in an original way & 0.75 & & & & \\
\hline Innovative behavior (Janssen, 2000) & & 4.90 & 1.001 & 0.93 & 0.67 \\
\hline I created new ideas for difficult issues (idea generation) & 0.74 & & & & \\
\hline $\begin{array}{l}\text { I sought out new working methods, techniques or instruments } \\
\text { (idea generation) }\end{array}$ & 0.85 & & & & \\
\hline $\begin{array}{l}\text { I made other participants outside our group enthusiastic about } \\
\text { our group's new ideas (idea promotion) }\end{array}$ & 0.77 & & & & \\
\hline $\begin{array}{l}\text { I transformed innovative ideas into useful application or } \\
\text { prototypes (idea realization) }\end{array}$ & 0.91 & & & & \\
\hline $\begin{array}{l}\text { I introduced innovative ideas into the group work in a } \\
\text { systematic way (idea realization) }\end{array}$ & 0.85 & & & & \\
\hline I evaluated the utility of innovative ideas (idea realization) & 0.80 & & & & \\
\hline $\begin{array}{l}\text { Participative safety (West, 1990; Kivimäki and Elovainio, } \\
\text { 1999) }\end{array}$ & & 5.60 & 1.227 & 0.95 & 0.82 \\
\hline Our group had a "we are in it together" attitude & 0.94 & & & & \\
\hline We all influenced each other & 0.94 & & & & \\
\hline $\begin{array}{l}\text { I felt myself understood and accepted by the other members of } \\
\text { the group }\end{array}$ & 0.93 & & & & \\
\hline I felt at ease with the members of our group & 0.93 & & & & \\
\hline $\begin{array}{l}\text { Suggestions and contributions of all group members were } \\
\text { respected and considered }\end{array}$ & 0.78 & & & & \\
\hline Support (West, 1990; Kivimäki and Elovainio, 1999) & & 5.23 & 1.303 & 0.92 & 0.73 \\
\hline $\begin{array}{l}\text { The group members provided practical support for new ideas } \\
\text { and their application }\end{array}$ & 0.76 & & & & \\
\hline $\begin{array}{l}\text { The group was all the time searching for fresh, new ways of } \\
\text { looking at problems }\end{array}$ & 0.91 & & & & \\
\hline The group took the time needed to develop new ideas & 0.83 & & & & \\
\hline $\begin{array}{l}\text { The people in the group co-operated in order to help develop } \\
\text { and apply new ideas }\end{array}$ & 0.92 & & & & \\
\hline Task orientation (West, 1990; Kivimäki and Elovainio, 1999) & & 5.06 & 1.346 & 0.87 & 0.69 \\
\hline $\begin{array}{l}\text { The group members questioned the basis of what the group was } \\
\text { doing }\end{array}$ & 0.89 & & & & \\
\hline $\begin{array}{l}\text { The group critically appraised potential weaknesses in what it } \\
\text { was doing in order to achieve the best possible outcome }\end{array}$ & 0.81 & & & & \\
\hline $\begin{array}{l}\text { The group built on each other's ideas in order to achieve the } \\
\text { best possible solution }\end{array}$ & 0.78 & & & & \\
\hline Vision (West, 1990; Kivimäki and Elovainio, 1999) & & 5.49 & 1.051 & 0.86 & 0.68 \\
\hline The group objective was clear to me & 0.84 & & & & \\
\hline The group members were committed to the objective & 0.86 & & & & \\
\hline $\begin{array}{l}\text { The objective was formulated so that it enabled exploration of } \\
\text { radically new possibilities }\end{array}$ & 0.78 & & & & \\
\hline
\end{tabular}


